\title{
Solar PV plant With Net-metering models
}

\author{
Sagar Telrandhe ${ }^{[1]}$, Nagendra Gupta ${ }^{[2]}$, Yogesh Mataghare $^{[3]}$,Akash Khatarkar ${ }^{[4]}$,Dr.G.H.Agrawal $^{[5]}$ \\ Students, Electrical Engineering Department, KDK College Of Engineering, Nagpur, India ${ }^{[1][2][3][4]}$ \\ Professor, Electrical Engineering Department, KDK College Of Engineering, Nagpur, India ${ }^{[5]}$
}

\begin{abstract}
The objective is to study India's power Scenario and different net-metering models with solar PV system. The paper introduces a widespread mechanism which enables consumers to reduce their electricity bills by utilizing self produced electricity from renewable energy resources; it also allows power producers to sell the excess energy produced to utilities or grid.
\end{abstract}

\section{Keywords: Solar, PV Systems, RTPV}

\section{INTRODUCTION}

With the increasingly urgent energy issues, the world attaches great importance to begin the development of new energy and related technology. At present large scale photovoltaic power generation and scale of renewable energy has become important parts of development strategy. They produce electrical power without harming the environment, by directly transforming the free unexhaustive source of energy, the solar energy into electricity .The photovoltaic installation mainly depends on the cost and efficiency of the generating system .the electricity generation from solar PV systems can also be fed to the distribution or transmission grid.

Net metering is a billing mechanism that credits solar energy system owners for the electricity they add to the

\section{INDIA'S POWER SCENARIO}

The electricity sector in India supplies the world's 6th largest energy consumer, accounting for $3.4 \%$ of global energy consumption by more than $17 \%$ of global population. The Energy policy of India is predominantly controlled by the Government of India's, Ministry of Power, Ministry of Coal and Ministry of New Renewable Energy and administered locally by Public Sector Undertakings (PSUs).

About $70 \%$ of the electricity consumed in India is generated by thermal power plants, $21 \%$ by hydroelectric power plants and $4 \%$ by nuclear power plants. More than $50 \%$ of India's commercial energy demand is met through the country's vast coal reserves. The country has also invested heavily in recent years in renewable energy utilization, especially wind energy. In 2010, India's installed wind generated electric capacity was 13,064 MW. Additionally, India has committed massive amount of funds for the construction of various nuclear reactors which would generate at least 30,000 MW. In July 2009, India unveiled a $\$ 19$ billion plan to produce 20,000 MW of solar power by 2020 . grid. This can be done by using a bi-directional meter which keeps record of electrical energy utilized by the consumer and how much excess amount of electricity is generated and fed to the grid. Instead of storing excess energy into the batteries ,it can be directly fed to the grid. Thus, reducing the cost of batteries from the cost of installation.

Net-metering should be provided to the customers in order to promote the solar installations. The schematic diagram for net-metering is as shown in Fig. 1.

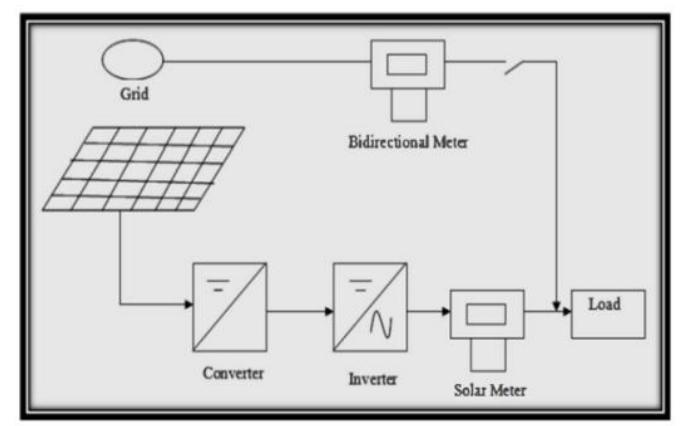

Due to the fast-paced growth of India's economy, the country's energy demand has grown an average of $3.6 \%$ per annum over the past 30 years. In December 2010, the installed power generation capacity of India stood at

Figure.1.Net metering system arrangement

165,000 MW and per capita energy consumption stood at $612 \mathrm{kWh}$. The country's annual energy production increased from about 190 billion $\mathrm{kWh}$ in 1986 to more than 680 billion $\mathrm{kWH}$ in 2006. The Indian government has set a modest target to add approximately $78,000 \mathrm{MW}$ of installed generation capacity by 2012 which it is

likely to miss. The total demand for electricity in India is expected to cross $950,000 \mathrm{MW}$ by 2030 .

According to a research report published by Citigroup Global Markets, India is expected to add upto $113 \mathrm{GW}$ of installed capacity by 2017.Further,renewable capacity might increase from $15.5 \mathrm{GW}$ to $36.0 \mathrm{GW}$. In the private 
sector, major capacity additions are planned in Reliance Power (35 GW) and CESC (7GW).

Electricity losses in India during transmission and distribution are extremely high and vary between 30 to $45 \%$. In 2004-05, electricity demand outstripped supply by $7-11 \%$. Due to shortage of electricity, power cuts are common throughout India and this has adversely effected the country's economic growth. Theft of electricity, common in most parts of urban India, amounts to $1.5 \%$ of India's GDP. Despite an ambitious rural electrification program, some 400 million Indians lose electricity access during blackouts. While 80 percent of Indian villages have at least an electricity line, just $52.5 \%$ of rural households have access to electricity.

In urban areas, the access to electricity is $93.1 \%$ in 2008. The overall electrification rate in India is $64.5 \%$ while $35.5 \%$ of the population still lives without access to electricity. According to a sample of 97,882 households in 2002 , electricity was the main source of lighting for $53 \%$ of rural households compared to $36 \%$ in 1993. Multi Commodity Exchange has sought permission to offer electricity future markets.

\section{III.SOLAR ROOF TOP PV PLANT}

Solar Rooftop PV (RTPV) systems are PV systems installed on rooftops of residential, commercial or industrial premises. The electricity generated from such systems could either be entirely fed into the grid at regulated feed-in-tariffs, or used for self consumption with the net-metering approach. A net-metering mechanism allows for a two-way flow of electricity wherein the consumer is billed only for the 'net' electricity (total consumption - own PV production) supplied by the DISCOM. Such RTPV systems could be installed with or without battery storage, and with one integrated net meter or two separate meters, one for export to grid and one for consumption. Irrespective of the commercial arrangement, RTPV systems offer several advantages. These include,

- Savings in transmission and distribution(T\&D) losses

- Low gestation time

- No requirement of additional land

- Improvement of the tail-end grid voltages, and reduction in system congestion with higher self consumption of solar electricity.

The excess amount of energy generated by this rooftop PV System can be fed to the grid, inorder to fulfill the energy demand. Figure 2: provides a block diagram of a grid connected solar PV system.

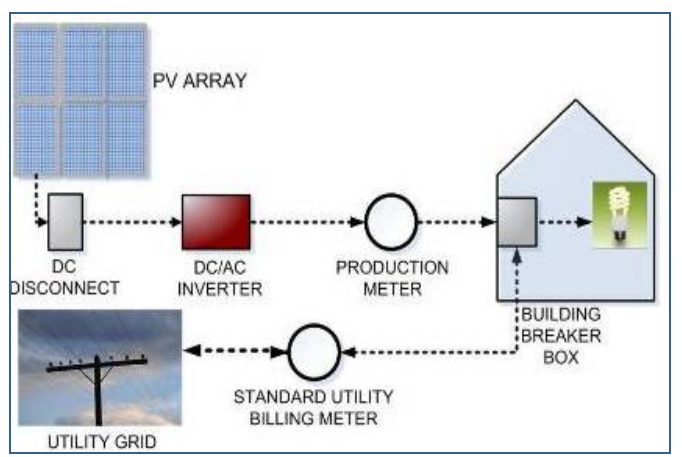

Figure 2: Block Diagram of Rooftop PV Plant

\section{IV.NET METERING}

Net metering is a billing mechanism that credits solar energy system owners for the electricity they add to the grid.

The concept of net metering involves recording the net energy between export of generated energy and import of energy from distribution licensee for a given period of time. This involves the usage of a bi-directional meter which has the facility to record both import and export values.

Under the net metering system, the excess energy generated by the solar photovoltaic plant at a given point of time is exported to the grid instead of being stored using a battery. However when there is a deficit in the power generated by the solar panels either during the night or a cloudy day, energy is drawn from the grid. At the end of the billing period, if more energy is exported to the grid than imported, then the distribution licensee pays the consumer at a pre-determined price. On the other hand if more energy is imported from the grid than exported, then the consumer pays the distribution licensee at a predetermined price. These prices usually vary from state to state.

Net metering had revolutionized the renewable generation through the concept of "running a meter backwards" and receiving credits for the same, in which excess energy exported to grid can be used to balance energy demand, peak load management, meeting renewable portfolio standards and leading towards a clean green production of electricity.

\section{NET METERING BUSINESS MODELS}

The net metering based rooftop solar projects facilitates the self-consumption of electricity generated by the rooftop project and allows for feeding the surplus into the network of the distribution licensee. The type of ownership structure for installation of such net metering based rooftop solar systems becomes an important parameter for defining the different rooftop solar models. In the international context, the rooftop solar projects have two distinct ownership arrangements. 
Self-owned arrangement wherein rooftop owner also owns the PV system and Third party ownership in which a developer owns the PV system and also enters into a lease/commercial arrangement with the rooftop owner. Both these models are relevant in the Indian context and have been discussed in the section below.

\section{- Self-owned, net-metering based rooftop PV net metering model}

In a self-owned, net-metering based rooftop PV model, the rooftop owner who is also the electricity consumer for the utility installs the rooftop solar system, either on its own or with the help of a system supplier and installer. The electricity generated by the system is first used to service consumer's captive load within the rooftop owner's premises. The solar power generated in excess of the owner's electricity consumption is fed into the grid through a net-meter, which is a bi-directional energy meter capable of registering both import and export of electricity. This net generation is then credited to the owner's account and adjusted subsequently against imports from the grid. Figure 3 provides a broad level structure of a self-owned net metering model.

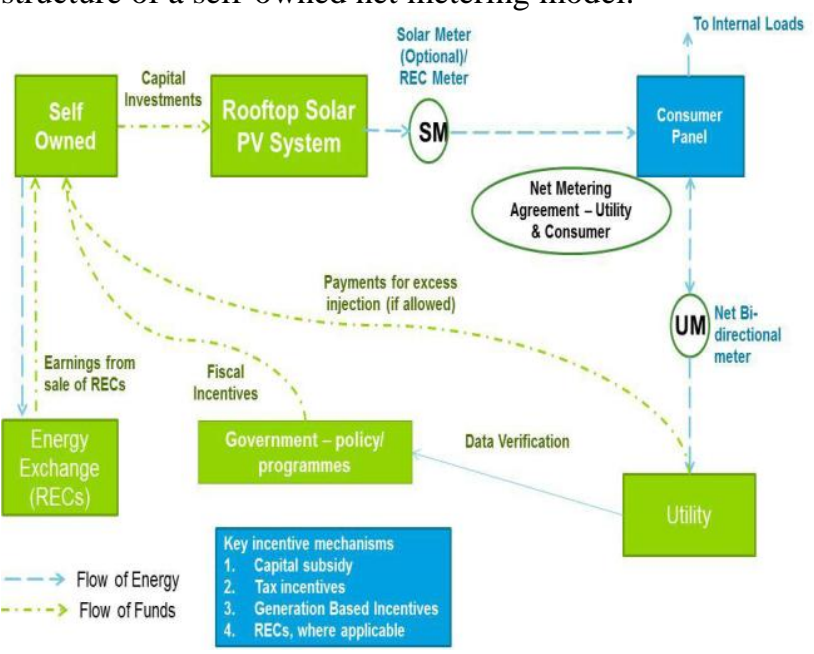

Figure 3 : Self owned net-metering model

For this model to work and to interconnect with the distribution utility, necessary provisions permitting netmetering through rooftop solar systems have to be adopted. The prevailing scenario of declining trends in solar tariff and increasing retail tariffs across most consumer categories like residential, commercial and industrial consumers in India, makes net metered projects financially viable over the medium term.

In the interim, there are several policy instruments like Generation Based Incentive (GBI) or capital subsidy which can be adopted to bridge the difference between the higher cost of solar generation and

applicable retail tariff for the consumer categories. There are several instances globally of this model having been implemented. For example, in Japan, the relatively higher retail tariffs combined with capital subsidy make such systems attractive for rooftop owners while in the case of the United States, tax rebates are the primary tool for incentives.

- $\quad$ Third party owned Rooftop PV net metering model

In the third party owned rooftop PV net metering model, the developers or intermediaries lease out solar PV systems to interested rooftop owners. This is a popular model for residential home owners in the United States, where turnkey installers lease rooftop systems to individual households who in turn pay them a monthly lease rental. The owner of the house provides the rooftop and commissions a turnkey installer to design and install the system. Alternatively, the installers can also offer an integrated service of leasing, commissioning and maintaining the systems to homeowners and guaranteeing standards of performance. The electricity generated from such a system is used to meet the rooftop owner's internal electricity needs while the excess generation is fed into the grid on net metering basis. This model has the following benefits.

Benefits to rooftop owner: The household owner avoids large upfront investment for the solar equipment and on occasion avoids assuming technology or performance risk of solar systems. Net-metering allows the rooftop owner to save on power consumed from the grid to the extent of solar generation. A part of savings in power consumption is shared with the developer by way of a lease rental.

Benefits to developer: The leasing company generates revenues by way of lease rental from the rooftop owner under a contract. As it continues to be owner of the equipment, it also qualifies for claiming depreciation on the capital cost of the PV systems, with associated direct tax benefits.

In order to make this model operational, electricity regulations need to be designed to remove specific barriers to participation of developers and intermediaries, who play an important role in the propagation of such systems. Under prevailing regulations in the Indian context, a third party owned system, unless specifically addressed, may result in an open access transaction, with implications of wheeling charges and surcharge relating to cross-subsidy. Figure 4 provides a broad level structure of a third party owned net metering model: 


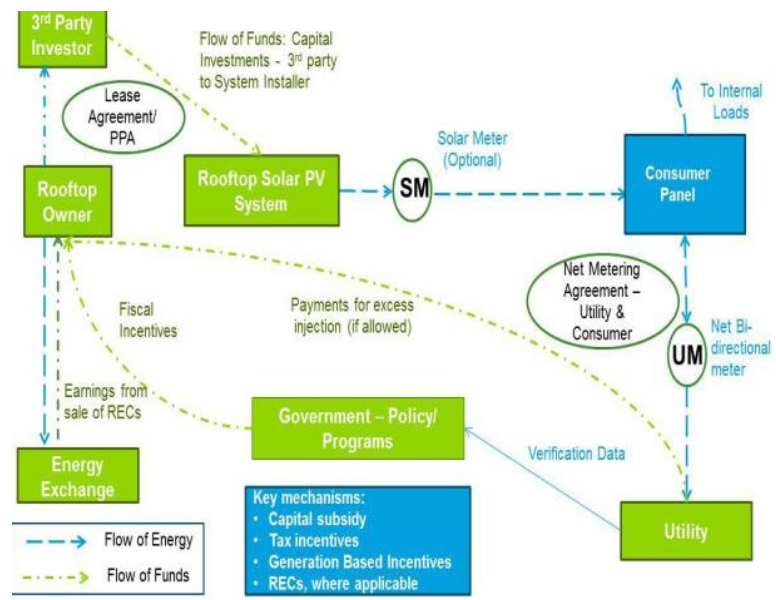

Figure 4 : Third party owned net metering model

\section{VI.CONCLUSION}

In this paper, it is concluded that according to power scenario of India there is a need to implement rooftop solar PV plant to fulfil the increasing energy demand. Also the comparison between the two models of rooftop PV plants which are self owned and third party owned PV model is helpful to implement the desired plan depending upon the capital cost, location, etc. It is analyzed that if both Generation based Incentive and State Subsidy is availed for residential consumers the payback period is comparably low which will be more beneficial for the consumers.

\section{REFERENCES}

[1] M.Sahanaa sree,S.Arunkumar, K. Kalidasa Murugavel , "Feasibility Study for the Net Metering Implementation in Residential Solar PV Installations across Tamil Nadu", 2014 ICCPETC.

[2] Y. Yang, H. Wang, and F. Blaabjerg, "Reduced junction temperature control during low-voltage ride-through for single-phase photovoltaic inverters," IET Power Electron., pp. 1-10, in press, 2014. DOI: 10.1049/ietpel.2013.0734. 
International Journal of Innovative Research in

Electrical, Electronics, Instrumentation and Control Engineering

ISO 3297:2007 Certified

Vol. 5, Issue 3, March 2017 